\title{
Gorlin Syndrome: Sequential Digital Dermoscopy of Palpebral Basal Cell Carcinomas in a Patient Treated with Vismodegib
}

\author{
Luis Mena-Vergara ${ }^{1}$, Mariana Silva-Astorga ${ }^{1}$, Carolina Carrasco-Cancino ${ }^{1}$, \\ Leoncio Muñoz-Uslar ${ }^{2}$
}

\begin{abstract}
1 Department of Dermatology, Faculty of Medicine, University of Chile, Santiago, Chile 2 Dermatology Service, Hospital del Salvador, Santiago, Chile
\end{abstract}

Key words: Gorlin syndrome, digital dermoscopy, palpebral basal cell carcinoma, vismodegib

Citation: Mena-Vergara L, Silva-Astorga M, Carrasco-Cancino C, Muñoz-Uslar L. Gorlin syndrome: sequential digital dermoscopy of palpebral basal cell carcinomas in a patient treated with vismodegib. Dermatol Pract Concept. 2022;12(1):e2022019. DOI: https://doi.org/10.5826/dpc.1201a19

Accepted: May 26, 2021; Published: January 2022

Copyright: $\odot 2022$ Mena-Vergara et al. This is an open-access article distributed under the terms of the Creative Commons AttributionNonCommercial License (BY-NC-4.0), https://creativecommons.org/licenses/by-nc/4.0/, which permits unrestricted noncommercial use, distribution, and reproduction in any medium, provided the original authors and source are credited.

Funding: None.

Competing interests: None.

Authorship: All authors have contributed significantly to this publication.

Corresponding author: Mariana Silva Astorga, Department of Dermatology, University of Chile, Santiago, Chile.

E-mail: valesilva.astorga@gmail.com

\section{Introduction}

Gorlin-Goltz syndrome (GS) is a multi-system genetic disorder, characterized by the development of jaw keratocystic odontogenic tumors (KOT) and multiple basal cell carcinoma (BCC) at young ages. Patients inherit a defective copy of PTCH1, a tumor suppressor gene, responsible for hedgehog pathway signaling (HPS) inhibition. PTCH1 mutations and loss of the remaining wild-type allele are also exhibited in $>90 \%$ of sporadic BCCs [1]. While most cases are amenable to surgery, locally advanced BCCs and unresectable tumors represent a complex scenario, in which HPS inhibitors may be a feasible treatment option with better clinical outcomes [1]. Digital images can be useful in following up BCC response to treatment [2].

We describe the involution of BCCs dermoscopic criteria recorded with sequential digital dermoscopy (SDD), in a patient with GS during treatment with vismodegib.

\section{Case Presentation}

A 58-year-old man with GS diagnosed at age of 7 years, presented with over 50 tumoral lesions and the presence of multiple BCCs in both eyelids was noted (Figure 1A). He had history of several surgical interventions to remove KOTs and BCCs with torpid evolution and development of retractile scars that in turn required advanced plastic surgical treatment to maintain functionality, resulting in aesthetic alterations (Figure 1A). Due to the high risk of causing severe ocular morbidity with a new surgery, vismodegib was initiated, resulting in a significant clinical response after 2 months. SSD was performed before and during treatment, and it revealed shrinking of palpebral tumors and regression of dermoscopic structures (Figures 1 and 2). 


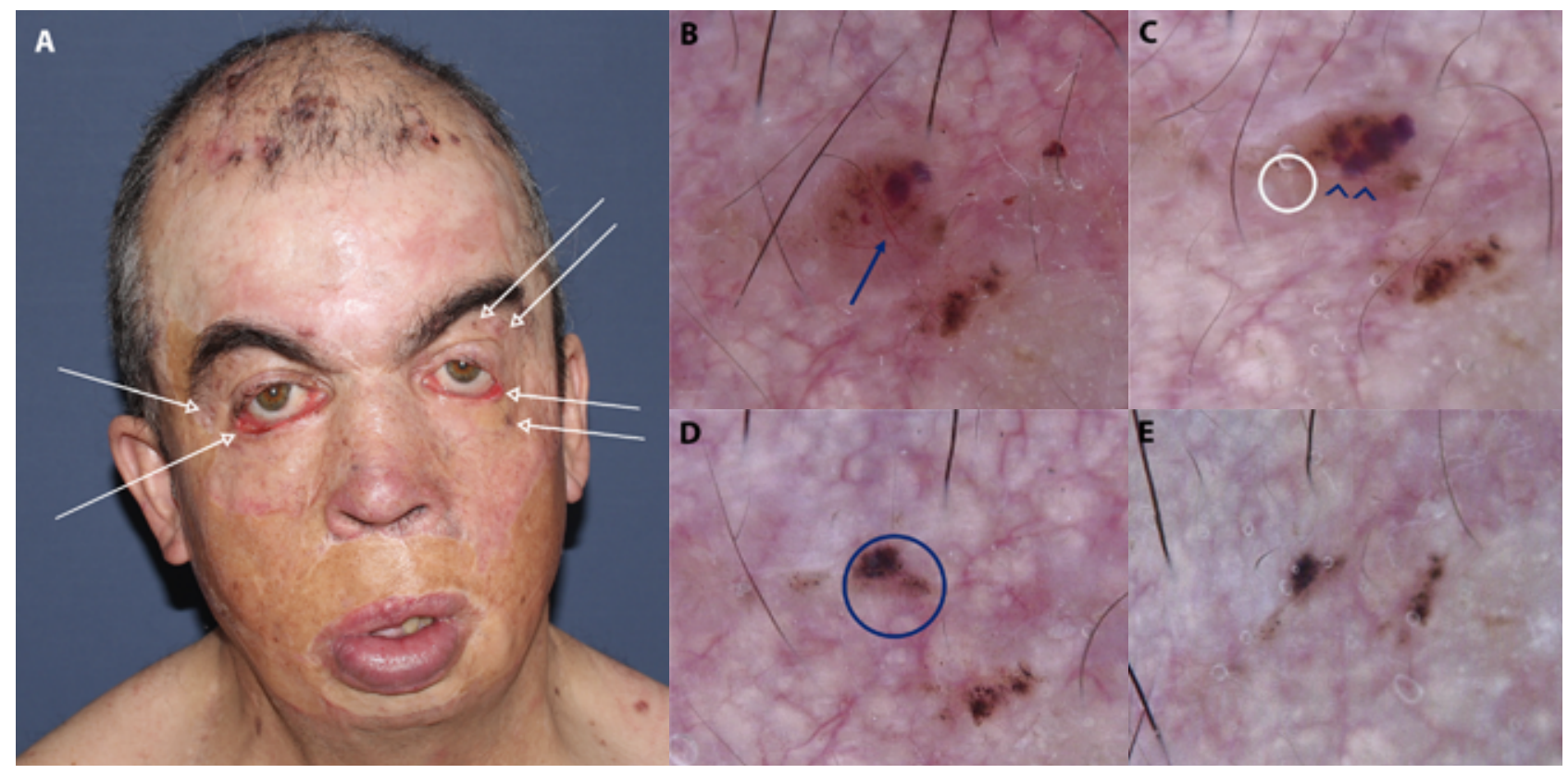

Figure 1. (A) Retractile scars due to several surgical interventions with secondary bilateral ectropion and ptosis. Multiple BCCs involving the scalp and periocular area (white arrows). (B) Pigmented BCC in superior left eyelid before vismodegib: typical dermoscopic structures, blue-gray globules, ovoid nest and arborizing vessels (blue arrow). (C) Week 2: Disappearance of some globules (white circle) and less notorious telangiectasia (blue arrows). (D) Week 7: Arborizing vessels are no longer visible (blue circle). (E) Week 8: Notable regression of BCC structures; only a few blue-gray globules persist.

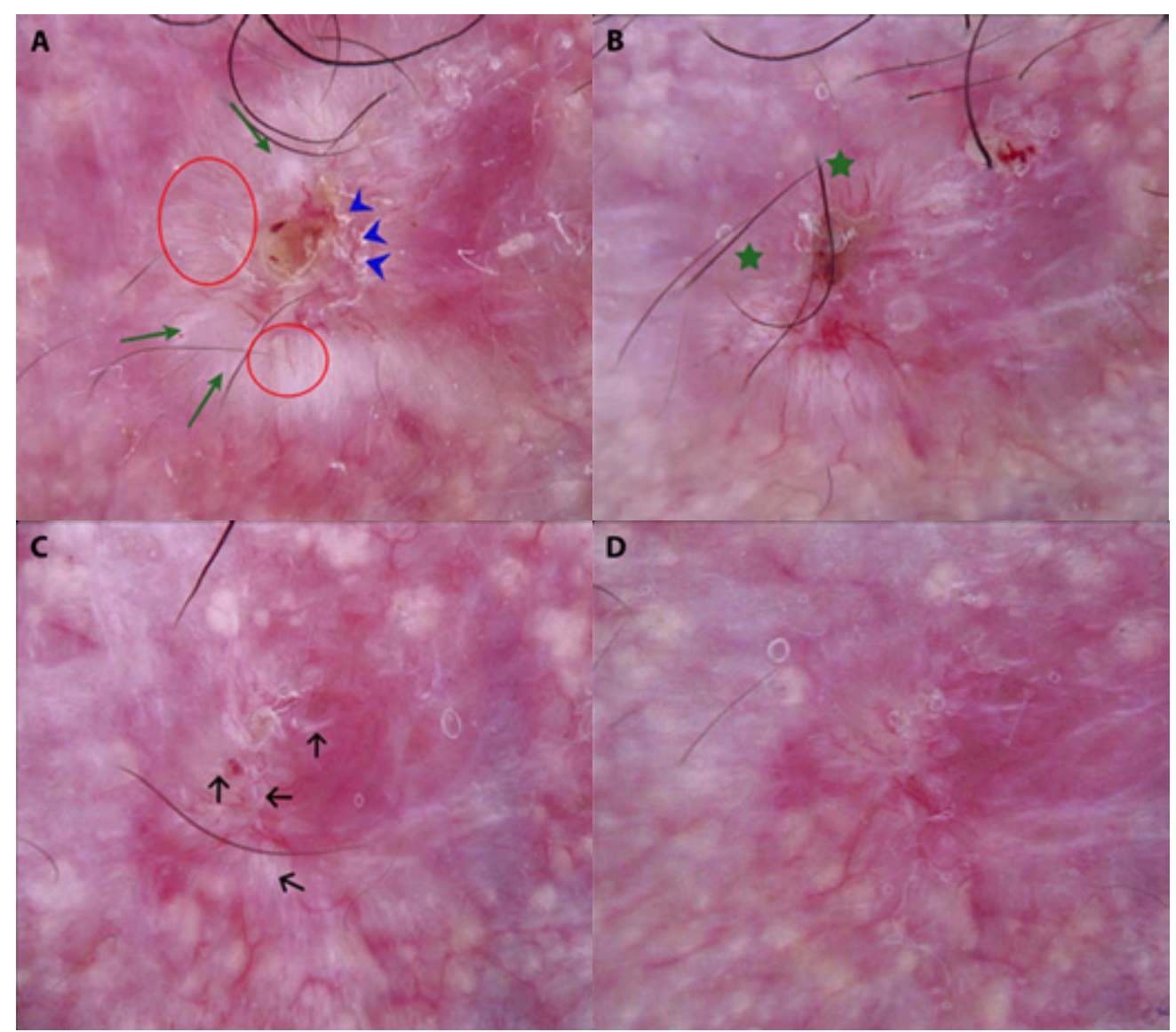

Figure 2. Nonpigmented basal cell carcinoma (BCC) in superior left eyelid. (A) Before vismodegib. Dermoscopic structures of a nonpigmented BCC: Multiple fine telangiectasia (red circle), crusting (blue arrows), whitish unstructured zones (green arrows). (B) Week 2: Notable less crusting and shrinking of whitish unstructured areas (green stars). (C) Week 7: A few fine telangiectasias persist, whitish areas are no longer visible, and some white shiny lines can be identified (black arrows). (D) Week 8: Almost no white lines and vessels remain. 


\section{Conclusions}

The presence of multiple BCCs is a hallmark finding in GS [1]. BCC accounts for $90 \%$ of malignant periocular tumors and represents $4.4 \%-18.0 \%$ of all BCCs [1]. Most periocular BCCs are curable with surgery; however, in patients with more extensive involvement, a surgical resection with curative intent may lead to substantial morbidity or deformity because of the need to remove periocular or orbital tissues that results in reduced functionality and quality of life [1]. Other therapeutic modalities such as photodynamic therapy and topical medications have been used as treatments for small or superficial BCCs. Radiotherapy should be avoided in GS [1].

Vismodegib is a first-in-class inhibitor of the HPS, and it reduces BCC tumor burden and blocks the growth of new BCCs in patients with GS [1]. Vismodegib has shown superior outcomes compared to other therapies; however, complete histologic clearance is not always achieved, and risk of progression or recurrence has been described after treatment cessation [1]. SDD is used for monitoring BCCs response to topical chemotherapy [2]. The presence or disappearance of
BCC dermoscopic criteria correlates with tumor persistence or histopathologic clearance respectively [2]. Blue-gray globules and ovoid nests can be detected for a longer period of time, whereas other typical structures decrease in size and number after chemotherapy initiation [2]. There is lack of evidence about SDD of BCCs in patients with GS treated with vismodegib.

SDD may help in detecting subtle changes and in facilitating the diagnosis of recurrence or progression of BCCs in patients treated with vismodegib or alternative treatments other than surgery.

\section{References}

1. Herms F, Lambert J, Grob JJ, et al. Follow-Up of Patients With Complete Remission of Locally Advanced Basal Cell Carcinoma After Vismodegib Discontinuation: A Multicenter French Study of 116 Patients. J Clin Oncol. 2019;37(34):3275-3282. DOI: 10.1200/JCO.18.00794. PMID: 31609670. Grajdeanu IA, Vata D, Statescu L, et al. Use of imaging techniques for melanocytic naevi and basal cell carcinoma in integrative analysis (Review). Exp Ther Med. 2020;20(1):78-86. DOI: 10.3892/ etm.2020.8620. PMID: 32508998; PMCID: PMC7271701. 